\title{
Congenital facial diplegia
}

\author{
M. LALlA, G. W. HOARE, AND R. PROSSER \\ Departments of Ophthalmology and Paediatrics, St. Woolos Hospital, Newport, Mon.
}

Congenital facial paralysis may occur alone or in association with other anomalies (DukeElder, 1964). The most common association is with the ocular motor nerves, particularly the VIth (Moebius syndrome).

Henderson (1939) reviewed 6r cases, showing a high incidence of motor palsies and other defects.

\section{Case report}

This patient, a boy aged 4 years, was referred to the Paediatric Department by his general practitioner who had noticed his stiff upper lip, and that he was unable to smile or wrinkle his face. In infancy he had had difficulty in sucking a bottle, but could feed from the breast. He was later able to swallow using a cup, without dribbling, but could not suck from a straw. He had had recurrent ocular infections until he was 2 or 3 years old.

\section{FAMILY HISTORY}

There was no family history of muscular or neurological disease, and no consanguinity. There were no complications during pregnancy and the confinement was normal.

\section{EXAMINATION}

The patient had an expressionless face with no movement of the facial muscles (Buster Keaton facies) (Fig. I). He was unable to close his eyes fully, smile, frown, raise his eyebrows, or purse his lips to whistle. Bell's phenomenon was observed on attempted closure of the eyes (Fig. 2). The mouth
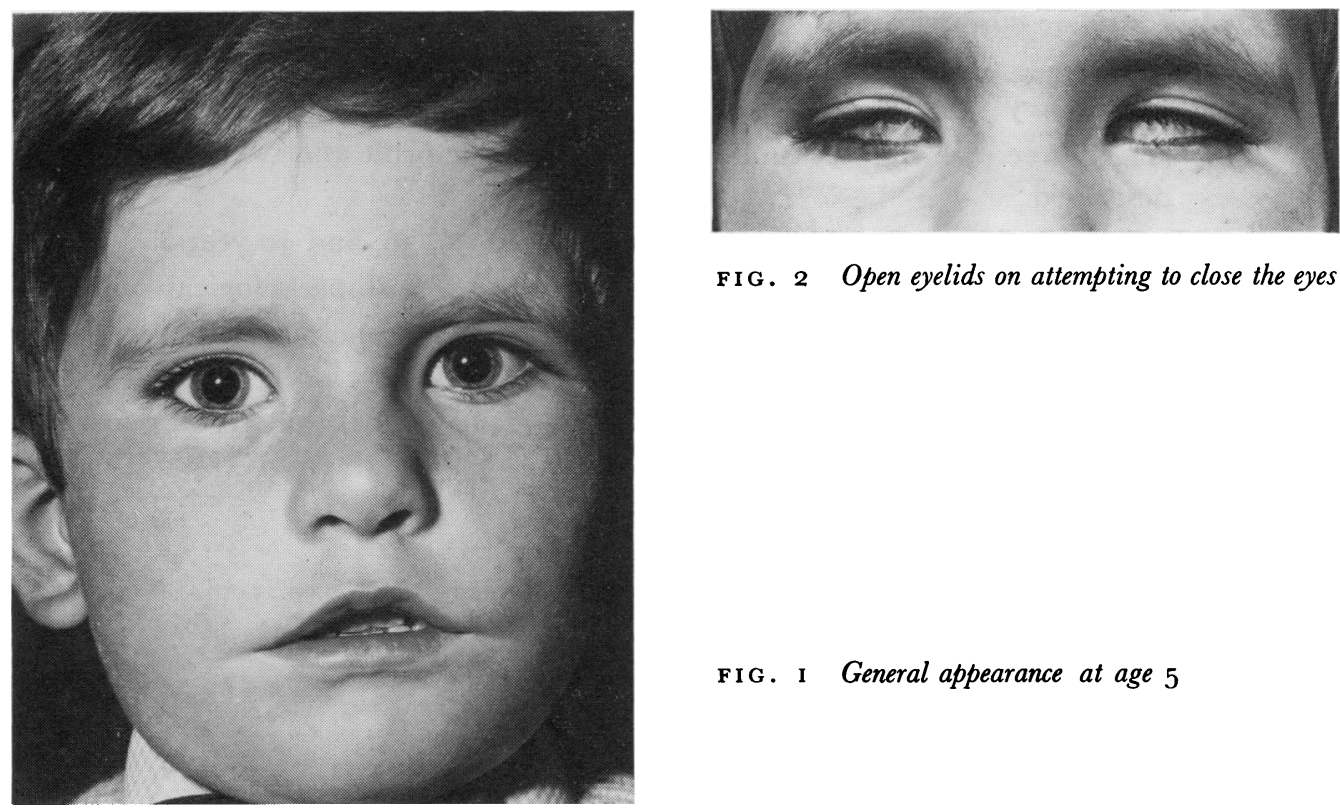

FIG. 2 Open eyelids on attempting to close the eyes

FIG. I General appearance at age 5 
was always slightly open and the upper lip prominent. The only movement of the mouth was that due to opening the jaw and to contraction of platysma in the neck. He had no difficulty in swallowing. The tongue was normal in size and could be protruded normally with no sign of twitching. The remainder of the examination gave normal results. Ocular movements were full. There was no nystagmus. Convergence was normal. There was watering of both eyes, but no discharge. Hearing was normal. The tear ducts were syringed and found to be patent.

\section{TREATMENT}

The symptoms were relieved by prescribing glasses with side-pieces to prevent dust or dirt from entering the eyes.

\section{Summary}

A case of congenital facial diplegia is described in which there was no involvement of the ocular muscles and no systemic defects.

We wish to thank the Department of Medical Illustration at the Royal Gwent Hospital for providing the illustrations.

\section{References}

DUKE-ELDER, S. (1964) “System of Ophthalmology", vol. 3, part 2, p. 1031. Kimpton, London HENDERSON, J. L. (1939) Brain, 62, 381 